\title{
Oil Prices and Stock Markets in Europe: A Sector Perspective*
}

\author{
Mohamed El Hedi Arouri \\ Philippe Foulquier \\ Julien Fouquau ${ }^{* * *}$
}

\section{Introduction}

Understanding the behaviour of stock prices and identifying the factors that affect their dynamics is an empirical question that has a decisive impact on portfolio management, asset and firm valuations, investment decisions, and other issues addressed by finance literature. Although there is a plethora of empirical work on asset pricing, the factors that play a role in stock return structures are still unclear. As oil prices have been highly volatile in recent years, now is surely the moment to examine their impact on stock market prices. One rationale for using oil price fluctuations as a factor affecting stock prices is that that, in theory, the value of stock equals the discounted sum of expected future cash-flows. These cash-flows are affected by macroeconomic variables that may be influenced by oil price changes.

Many papers have studied the link between oil prices and equity markets [Jones and Kaul (1996), Huang et al. (1996), Sadorsky (1999), Park and Ratti (2008), and Apergis and Miller (2009)]. All focus on empirical evidence at the market level. They attempt to determine if, in the aggregate market level, there is a significant short-term relationship between the two series. In this paper, we take a different perspective and explore the linear and nonlinear long-term relationships between oil prices and stock prices at the disaggregated sector level, an issue that has not yet been examined in the literature. The question we endeavour to answer is whether oil price changes (increases and decreases) affect sector stock prices equally.

Corresponding author. We thank two anonymous reviewers and Stéphane Grégoir for very helpful comments and suggestions on an earlier version of the paper. The usual disclaimer applies.

** LEO-Université d'Orléans \& EDHEC Business School, mohamed.arouri@univ-orleans.fr

*** EDHEC Business School, philippe.foulquier@edhec.edu

${ }^{* * \star *}$ Rouen Business School \& CGEMP-LEDa, jfq@ rouenbs 
Studying the long-term effects of oil price changes on stock prices by sector instead of in the aggregate market level is important for several reasons. First, stock prices for the market as a whole may mask the heterogeneous performance of various sectors. Furthermore, sector sensitivities to changes in oil price can be asymmetric, as some sectors may be more severely affected by these changes than others. A sector's sensitivity to oil prices depends on whether oil serves as its input or output, its exposure to indirect oil price effects, competition and concentration, and its capacity to absorb and pass on oil price risk to its consumers. Second, the industrial composition of the market varies from one European market to another. Large, mature markets (France and Germany) have more diversified industries, whereas small markets (Switzerland) are usually concentrated on a few industries. It is thus interesting to know whether sector indices rather than national indices are sensitive to oil price fluctuations. Finally, from the point of view of portfolio management, indentifying the heterogeneity of sector sensitivity to oil implies that there are sectors that can still provide a channel for achieving the benefits of international diversification during large swings in oil prices.

We investigate the relationship between oil prices and stock markets over the post-1997 Asian financial crisis: from January 01, 1998, to November 13, 2008. Over this period of turbulent but globally increasing oil prices and stock markets, increases in oil prices were, at the same time, indicative of higher production costs and inflation pressure, and often synonymous with higher expected economic growth and higher consumer and investor confidence. We proceeded in different steps. First, we have tested for the stationnarity of the oil and stock market prices. Our results show that all series are nonstationary. We then run classic cointegration tests to check for a stochastic trend common to the oil price and the aggregate European stock market index. Our findings are that there is no cointegrating relationship between the two series. We thought that these results were the result of stock market aggregation, which may mute sector stock price sensitivities to oil price changes. Thus, we applied the classic linear cointegration tests to twelve European sector indices. Again, our results conclude that, in most cases, there are no traditional cointegrating relationships. These findings are counterintuitive, in particular for sectors, such as Gas \& Oil and Industrials, highly sensitive to oil price changes.

Some papers, however, have shown that the link between oil and economic activity is not entirely linear and that negative oil price shocks (price increases) tend to have a greater impact on growth than do positive shocks [Mork (1989), Hamilton (2003), Zhang (2008), Lardic and Mignon (2006, 2008) and Cologni and Manera (2009)]. So we should expect oil prices to affect stock markets in a nonlinear fashion as well. Finally, we used asymmetric cointegration tests to check for the existence of long-term relationships. Our results show the existence of significant asymmetric cointegrating relationships between oil prices and several European sector stock indices. 
The rest of the paper is organized as follows. Section 2 presents the transmission channels through which oil price shocks may affect macroeconomic variables and stock prices and discusses the related literature. The methodology is introduced in Section 3. Section 4 presents the data and discusses the empirical results. Summary conclusions and policy implications are provided in Section 5 .

\section{Oil, Economic Activity and Stock Prices: Transmission Channels and Related Works}

There is a large body of work on links between oil prices and macroeconomic variables. Theoretically, oil price changes may affect economic activity through various channels. For instance, oil price fluctuations may have effects on the basic production input availability and investment costs (supply-side effects), on the terms of trade and wealth transfer from oil consumers to oil producers, on the firm's production structures and unemployment, on monetary policies, interest rates and inflation, and on consumption opportunities, costs and consumer demand and sentiment (demand-side effects) [Hamilton (1983), Jones et al. (2004) and references therein]. Empirically, several studies have shown that increases in the price of oil have significant negative effects on economic growth for several developed and emerging countries [Cunado and Perez de Garcia (2005), Balaz and Londarev (2006), Gronwald (2008), and Cologni and Manera (2008)]. However, in the last years, it seems that there is some evidence of a reverse causality between oil price and macroeconomic variables: economic growth would be associated with an increase in the oil price because of growing demand [Barsky and Killian (2004), and Killian (2008, 2009)].

Furthermore, some theoretical and empirical work has suggested that the relationship between oil prices and economic activity is not entirely linear. Authors have focused mainly on three possible explanations of the asymmetric responses of macroeconomic variables to oil price shocks: counter-inflationary monetary policy responses to oil price increases, sector shock transmission mechanisms, and investment uncertainty [Hamilton (1988), Mork et al. (1994), Ferderer (1996) and references therein]. Mork (1989) extends the analysis of Hamilton (1983) and shows that there is an asymmetric relationship between oil prices and output growth. He establishes, in particular, that economic growth has a significant negative correlation with oil price increases, but an insignificant positive correlation with oil price decreases. More recently, Davis and Haltiwanger (2001) distinguish between aggregate transmission mechanisms (effects of increases in the price of oil on potential outcome, income transfer and sticky wages) and allocative transmission mechanisms (effects of oil price changes on the closeness of the match between firms' 
desired and actual levels of labour and capital). The allocative transmission mechanisms should operate asymmetrically since both oil price increases and decreases would change firms' desired employment structures, whereas the aggregate channels should operate symmetrically. Based on this analysis, Davis and Haltiwanger (2001) show that the responses of the economy to oil price increases are considerably larger than those to oil price decreases. Lee and Ni (2002) establish that more energy-intensive industries tend to experience oil price shocks as supply shocks (aggregate impacts) and less energy-intensive industries as demand shocks (allocative impacts). Finally, the asymmetric relationship between oil shocks and economic growth is supported by a series of more recent empirical works employing more robust econometric techniques [Hamilton (2003), Zhang (2008), Lardic and Mignon $(2006,2008)$ and Cologni and Manera (2009)]. These works confirm that oil price increases appear to retard aggregate economic activity by more than oil price decreases stimulate it. However, as we mentioned above, in the last years economic growth was associated with increases in oil prices because of higher demand and investor sentiment [Barsky and Killian (2004), and Killian $(2008,2009)]$.

In sharp contrast to the body of work investigating the link between oil prices and economics activity, the work done on the relationship between oil price variations and stock markets is very scant. For the most part, this work considers the macroeconomic effects of oil price fluctuations discussed above as the main channels through which oil price changes may affect stock prices. As financial markets are more efficient than real markets and highly sensitive to news, it is reasonable to expect that stock markets absorb information about the consequences of oil price changes and reflect it quickly into stock prices. Indeed, in theory, the value of stock is equal to the discounted sum of expected future cash-flows. These discounted cash-flows reflect instantaneously current and expected changes in economic conditions (e.g., inflation, interest rates, production costs, income, demand, economic growth, and investor and consumer confidence) and macroeconomic events likely to be influenced by oil price fluctuations. Accordingly, oil price changes may impact stock prices.

Furthermore, one should expect the asymmetry between oil price changes and macroeconomic variables to induce some nonlinearity in the responses of stock prices to oil price fluctuations. For instance, the asymmetric reactions of monetary authorities to oil price changes may nonlinearly affect stock prices through their impact on real interest rates and inflation. Of course, the other asymmetric transmission channels are active in the case of stock markets: sector shock transmission mechanisms, investment uncertainty, allocative transmission mechanisms and transaction costs. Moreover, the asymmetric responses to oil price changes may be stronger in the case of financial markets, as the latter are more efficient than real markets, so stock prices should quickly incorporate the expected asym- 
metric impact of oil price changes on economic variables. In addition, oil price changes influence industries differently, as we discussed in the introduction to the paper, and for that reason the nature of the relationships between oil price changes and sector stock prices is complicated and should vary considerably from one industry to another. Finally, these asymmetric responses may also be the result of psychological effects. Indeed, a sharp rise in the price of oil may have a more profound impact on investors and on sector stock prices than a sharp fall.

The pioneering paper by Jones and Kaul (1996) uses the standard cash flow dividend valuation model to test for the reaction of international stock markets (Canada, UK, Japan and US) to oil price changes. The paper finds that for the US and Canada this reaction can be accounted for entirely by the impact of the oil shocks on cash-flows. The results for Japan and the UK were inconclusive. Using an unrestricted vector autoregressive (VAR) model, Huang et al. (1996) find no evidence of a relationship between oil prices and market indices such as the S\&P500. In contrast, Sadorsky (1999) applies an unrestricted VAR with GARCH effects to American monthly data and shows a significant short-term relationship between the unexpected oil price changes and the returns on the aggregate S\&P 500 stock market index. In particular, he shows that oil prices have asymmetric effects: on average, positive oil shocks account for more of the forecast error variance in aggregated stock returns than do negative shocks. Relying on nonlinear causality tests, Ciner (2001) provides evidence that oil shocks affect stock index returns in the US in a non-linear manner, which is consistent with the documented influence of oil on economic activity. Park and Ratti (2008) show that oil prices have a negative impact on stock returns in the US and twelve European countries, whereas stock markets in Norway, an oil exporter, respond positively to increases in the price of oil. More recently, Apergis and Miller (2009) have examined whether structural oil-market shocks affect stock prices in eight developed countries. Using different econometric techniques, the authors find that international stock market returns do not respond overmuch to oil price shocks.

Some recent papers have focused on major European, Asian and Latin American emerging markets. The results of these studies show a significant short-term link between oil price changes and emerging stock markets. Using a VAR model, Papapetrou (2001) shows a significant relationship between oil price changes and stock markets in Greece; with an international multifactor model, Basher and Sadorsky (2006) reach the same conclusion for other emerging stock markets. However, Maghyereh (2004) investigates the relationships between oil prices and stock market prices in twenty-two emerging markets and finds no impact on stock index returns in those countries. Hammoudeh and Choi (2006) examine the long-term relationship among the Gulf Corporation Council stock markets in the presence of the US oil market, the S\&P 500 index and the US Treasury bill rate. 
They found that the T-bill rate has a direct impact on these markets, whereas oil and the S\&P 500 have indirect effects. Finally, Nandha and Hammoudeh (2007) examine the short-term reaction of stock markets in the Asia-Pacific region to oil price shocks. They find the Philippines and South Korean stock markets to be oil-sensitive only when the price is expressed in local currency. However, the authors show that none of the countries they study is sensitive to oil prices expressed in US dollars.

Very few studies have investigated whether oil price changes impact stock prices by sector. These studies have exclusively examined the shortterm relationships between the two variables. In addition, most of these works are country-specific and thus do not provide a global perspective. For instance, Sadorsky (2001) and Boyer and Filion (2007) show that oil price increases positively affect the stock returns of Canadian Oil \& Gas companies. El-Sharif et al. (2005) reach the same conclusion for Oil \& Gas returns in the UK. However, the authors show that non-Oil \& Gas sectors are weakly linked to oil price changes. More recently, Nandha and Faff (2008) study the short-term link between oil prices and thirty-five DataStream global industries and show that oil price rises have a negative impact for all industries except Oil \& Gas. Furthermore, their results support a little evidence of asymmetry in the short-term relationships between oil and stock returns. Nandha and Brooks (2009) investigate the reaction of the transport sector to oil prices in thirty-eight countries around the world. Their results suggest that oil prices do have some role in determining the transport sector returns for developed countries. For Asian and Latin American countries, however, there appears to be no such evidence.

Taken together, the results from the work on the short-term relationships between oil and sector stock returns differ from one country to another and from one sector to another depending on whether oil is an input or an output for the sector. To the best of our knowledge, there is no previous empirical investigation of the long-term relationship between oil and stock markets at sector level. Furthermore, as we can see, the results of previous work on the link between oil and stock markets are too heterogeneous to provide a general consensus. The conclusions of these works could be the result of two facts. First, all the past empirical investigations of the longterm relationships between oil and stock market prices have focused on the general aggregate index of the individual markets (national and/or regional indices) rather than on individual sectors. As we argued in the introduction, stock market aggregation may mute sector sensitivities to oil price changes. Second, most previous work has used the classic cointegration tests. However, these tests are not powerful enough to detect nonlinear links. As we have mentioned above, recent papers argue that there is an asymmetric relationship between oil prices and economic activity. This suggests that asymmetric links between oil prices and the stock market could be uncovered. This article extends the understanding of the relationship between oil 
prices and the stock markets in Europe by testing for linear and asymmetric long-run linkages at both aggregate and sector levels.

\section{$3 \quad$ Methodology}

The aim of this article is to check for linear and asymmetric long-term relationships between oil prices and European sector stock indices. We proceed in two steps. First, we test for traditional linear cointegration using the Engle and Granger (1987) approach. Second, we use a method similar to that of Schorderet (2004) to test for asymmetric cointegration.

We briefly present the original asymmetric cointegration approach of Schorderet (2004) in Appendix A. ${ }^{1}$ Here, we illustrate how to use such approach to test for asymmetric cointegration between oil prices and sector market prices. For illustration purposes, consider the logarithm of the oil prices series $\left\{L_{o i l}\right\}_{t=0}^{T}$. We must first decompose this time series into positive and negative parts:

$$
L o i l_{t}=\operatorname{Loil}_{0}+L o i l_{t}^{+}+\operatorname{Loil}_{t}
$$

where $L o i l_{0}$ is the initial value and:

$$
L o i l_{t}^{+}=\sum_{i=0}^{t-1} 1\left\{\Delta \operatorname{Loil}_{t-i} \geq 0\right\} \Delta \operatorname{Loil}_{t-i} \text { and } \operatorname{Loil}_{t}=\sum_{i=0}^{t-1} 1\left\{\Delta \operatorname{Loi}\left(l_{t-i}<0\right)\right\} \Delta \operatorname{Loil}_{t-i}
$$

$1\{$.$\} is the indicator function taking 1$ if the event in brackets occurs and zero otherwise.

To test for asymmetric cointegration between oil prices and sector stock indices, we can estimate the following long-term relations:

$$
\begin{aligned}
& \text { LStock }_{t}^{-}+\Delta \text { LStock }_{t}^{+}=\beta_{0}^{-}+\beta_{1}^{-} \text {LOil }_{t}^{-}+\xi_{1 t} \\
& \text { LStock }_{t}^{+}+\Delta \text { LStock }_{t}^{-}=\beta_{0}^{+}+\beta_{1}^{+} \text {LOil }_{t}^{+}+\xi_{2 t}
\end{aligned}
$$

where $L$ Stock $k_{t}^{+}$, LStock $k_{t}^{-} L_{O i l_{t}^{+}}$and $L O i \bar{l}_{t}$ are the positive and the negative components of logarithms of sector stock prices and the oil prices respectively. If $\xi_{1 t}$ and or $\xi_{2 t}$ are stationary processes, the time series $L O i l_{t}$ and $L$ Stock $k_{t}$ are said to be asymmetrically cointegrated. ${ }^{2}$

1 The asymmetric cointegration approach of Schorderet (2004) has been applied in several recent studies; see Lardic and Mignon $(2006,2008)$ and Shen et al. (2007), for instance.

2 We are grateful to an anonymous referee and Stéphane Grégoir for very helpful comments and suggestions that have greatly motivated this part of the paper. We also have to mention that by construction of variables, the Schorderet's model cannot be adapted to directly investigate cointegrating relationships between $\mathrm{LOil}_{t}^{+}$(respectively, $\mathrm{LOil}_{t}$ ) and $\mathrm{LStock}_{t}^{-}$(respectively, LStock ${ }_{t}^{+}$). 
According to Schorderet (2004), various extensions of models (3) and (4) are possible. For instance, it is possible to include an intercept term. This method has three main advantages: the linear cointegration is not required (in contrast, it is required in the threshold cointegration approach ${ }^{3}$ ); traditional cointegration tests can be applied to (3) and (4) and we could have a cointegrating relationship which "operates" in only one direction (if only $\xi_{1 t}$ or $\xi_{2 t}$ is stationary).

However, this approach could not be relevant as specifications in (3) or (4) are suspected to be misspecified. Indeed, in equation (3) (in equation (4) respectively), the transformed series of stock and oil prices are decreasing (increasing) functions of time. Thus, it appears suitable to introduce a linear trend in equations (3) and (4). Then, on the basis of equations (5) and (6), we can test for asymmetric cointegrating relationships by implementing the traditional Engle and Granger test procedure and using the corresponding Phillips-Ouliaris (1990) critical values:

$$
\begin{aligned}
& \text { LStock }_{f}^{-}+\Delta \text { Ltock }_{t}^{+}=\beta_{0}^{-}+\beta_{1}^{-} \text {LOil }_{t}^{-}+\beta_{2} t+\xi_{1 t} \\
& \text { LStock }_{f}^{+}+\Delta \text { LStock }=\beta_{0}^{+}+\beta_{1}^{+} \text {LOil }_{t}^{+}+\beta_{2} t+\xi_{2 t}
\end{aligned}
$$

Alternatively, we can improve equations (3) and (4) by introducing the European Industrial Production $(I P)$ to filter out common macroeconomic influences. Indeed, as we mentioned in the introduction, during our sample period increasing oil prices were often associated with a booming economy and increasing stock markets. This leads us to base our asymmetric cointegration tests on equations (7) and (8):

$$
\begin{aligned}
& \text { LStock }_{t}^{-}+\Delta \text { LStock }_{t}^{+}=\beta_{0}^{-}+\beta_{1}^{-} \text {LOil }_{t}^{-}+\beta_{2} I P_{t}+\xi_{1 t} \\
& \text { LStock }_{t}^{+}+\Delta \text { LStock }=\beta_{0}^{+}+\beta_{1}^{+} L O i l_{t}^{+}+\beta_{2} I P_{t}+\xi_{2 t}
\end{aligned}
$$

In all cases, the asymmetric cointegration exists, if the residuals $\xi_{1 t}$ or $\xi_{2 t}$ are stationary.

\section{$4 \quad$ Data and Empirical Results}

\subsection{Data}

Our goal is to investigate the existence of a long-term relationship between oil prices and sector stock market returns in Europe. Our sample data include the Dow Jones (DJ) Stoxx 600 and twelve European sector indices,

3 Threshold cointegration models need linear cointegration because the first step is to test the null hypothesis of linear cointegration against threshold cointegration [Choi and Saikkonen (2004)]. 
namely Automobile \& Parts, Financials, Food \& Beverages, Oil \& Gas, Health Care, Industrials, Basic Materials, Personal $\&$ Household Goods, Consumer Services, Technology, Telecommunications and Utilities. Introduced in 1998, the Dow Jones Stoxx 600 sector indices aim to represent the largest European companies in each of the most important industries; they currently cover Austria, Belgium, Denmark, Finland, France, Germany, Greece, Iceland, Ireland, Italy, Luxembourg, the Netherlands, Norway, Portugal, Spain, Sweden, Switzerland and the United Kingdom. The sector indices offer an alternative view of the performance of the European stock markets and are often considered by investors. We collect stock market data from the Datastream database.

Figure 1. European market index (DJ Stoxx 600) and crude oil price (Brent)

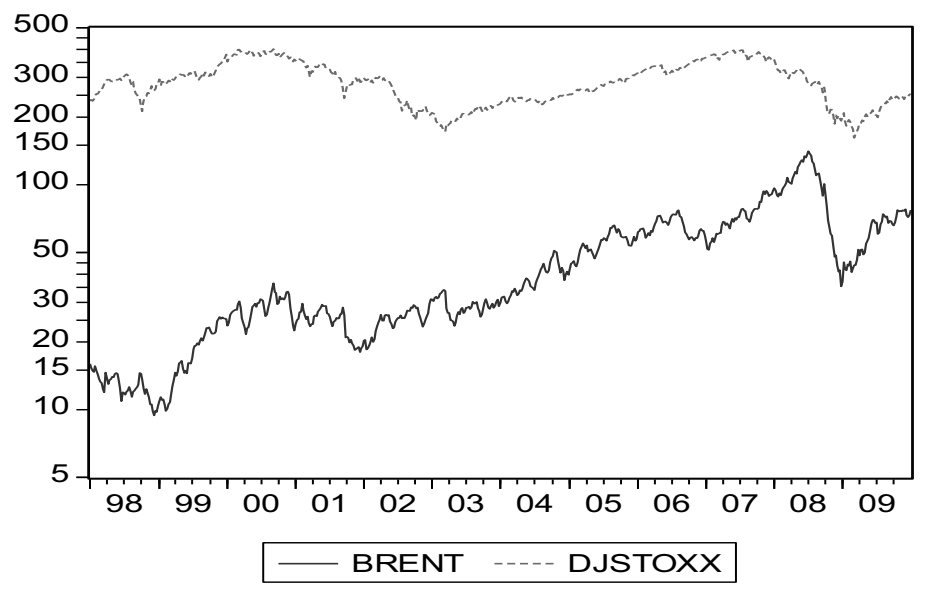

We think that weekly data may better capture the interaction of oil and stock price changes than daily or monthly data. On the one hand, the use of weekly data in the analysis instead of daily data significantly reduces any potential biases that may arise such as the bid-ask effect, non-synchronous trading days, etc. On the other hand, monthly data may have some bearing on asymmetry in responses of stock returns to oil price changes. In this schema, we make use of weekly stock market sector indices over the period from January 01, 1998, to November 13, 2008, and examine their sensitivity to the recent oil price boom after the 1997 Asian financial crisis. Over this sample period, increases in oil prices were, at the same time, indicative of higher production costs and inflation pressure, and often synonymous with a booming economy and stronger business performance (see Figure 1). 
For oil, we use the weekly Brent crude oil price obtained from the Energy Information Administration (EIA). The Europe Brent is one of the major international oil benchmarks. We express Brent oil prices in euros using euro/dollar exchange rates from Datastream.

\subsection{Unit root tests}

We must first test for the presence of unit roots in the oil price and stock price series in logarithm. For this purpose, we apply successively three standard tests: the augmented Dickey Fuller (ADF), the Phillips Perron (PP) and the Kwiatkowski et al. (1992) (KPSS) test. Unlike the first two tests, ${ }^{4}$ the KPSS test has the advantage of being based on the null hypothesis of series stationnarity.

In performing an ADF test, we will face two practical issues. First, we have the choice to include a constant, a constant and a linear time trend, or neither in the test regression. Indeed, including irrelevant regressors in the regression will reduce the power of the test to reject the null of a unit root. Then, we apply a Fisher test strategy to select the optimal model. Under the null hypothesis, the critical values of this test are not standard but they have been computed by Dickey Fuller (1981). Second, we will have to specify the number of lagged difference terms of the dependent variable to be added to the test regression. The usual advice is to include a number of lags sufficient to remove serial correlation in the residuals, so we take the number of lags that minimize information criteria.

To specify the PP or KPSS test, we have to select the regression form to test as in the ADF test. ${ }^{5}$ We must then choose the kernel and the bandwidth parameter needed to estimate the residual spectrum at frequency zero. The usual solution is to use the Bartlett kernel and the Newey-West (1994) data-based automatic bandwidth parameter method.

In Table 1, we show the results of the three unit root tests. The tests give the same conclusion that the series are integrated of order (1) and in most cases at the $1 \%$ significance level. In other words, our series are nonstationary. Next, we test for the existence of stochastic trends common to oil prices and stock markets in Europe.

4 The ADF and PP test are based on the null hypothesis of a unit root.

5 Two alternative test regressions are only possible in the KPSS test: inclusion of a constant or a constant and a trend. We choose the same or the close form as in ADF test regression. 


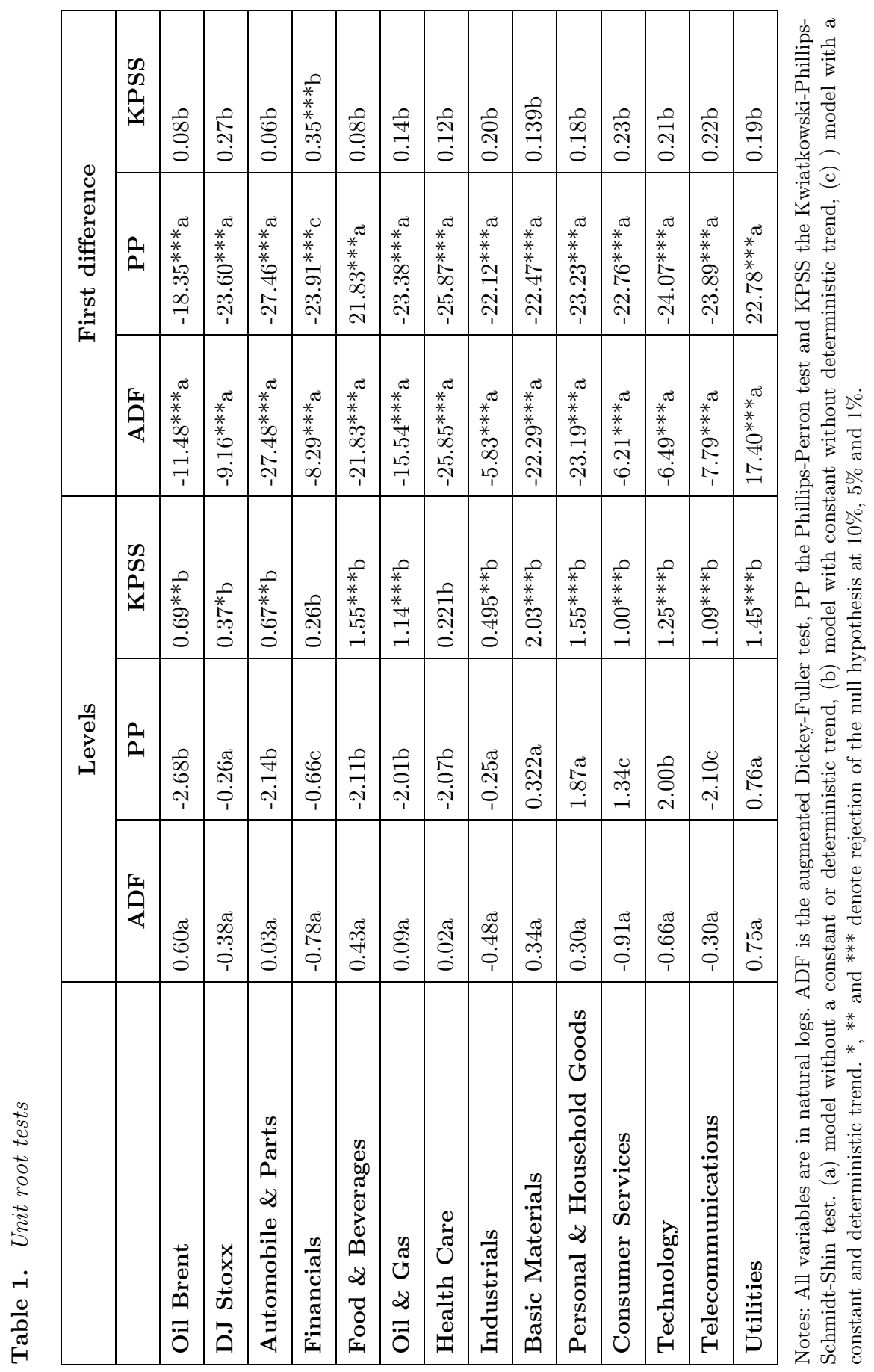




\subsection{Traditional cointegration tests}

In the second step of our analysis, we proceed to standard cointegration tests between the oil prices and stock market series. In this respect, we begin by applying the Engle and Granger (1987) test. For comparison purposes to the asymmetric relationships (equations 5-8), we estimate the equations (9) and (10) by OLS and test the unit root hypothesis in the residuals:

$$
\begin{aligned}
& \text { LStock }_{t}=\beta_{0}+\beta_{1} \text { LOil }_{t}+\beta_{2} t+\xi_{t} \\
& \text { LStock }_{t}=\beta_{0}+\beta_{1} \text { LOil }_{t}+\beta_{2} I P_{t}+\xi_{t}
\end{aligned}
$$

By definition, there is cointegration if the residual sequence $\varepsilon_{t}$ is stationary. To this end, we use the same strategy that we have applied in the unit root tests: the ADF and PP tests. To confirm our results, we have also applied cointegration tests using the methodology developed by Johansen (1991). Results are shown in Table 2. ${ }^{6}$

The results for the aggregate European stock market index (DJ Stoxx) indicate that there is no significant long-term relationship between oil prices and stock returns in Europe. However, these results must be taken with great caution. In fact, DJ Euro Stoxx is an aggregate market index which aims to provide a representation of sector leaders in eighteen European countries. These sectors may have different negative and positive sensitivities to oil price changes. Thus, aggregation of these different sectors may mute sector stock sensitivities to oil price changes. For this reason, we have applied the classic linear cointegration tests to twelve European sector indices. The linear cointegration hypothesis is not rejected at the $10 \%$ level for Food $\&$ Beverages sector according to Johansen test and for Technology and Telecommunications based on ADF and PP tests. For all the other sectors, the linear cointegration is strongly rejected based on the three cointegration tests.

The absence of significant long-term relationships between oil prices and most sector stock prices in Europe is counterintuitive, as most European countries are oil-importing countries and their economies are thus sensitive to the prices of oil and related energy products. In fact, we expected swings in oil prices to make a significant impact on stock prices in different sectors. As we have noted, however, some recent papers have shown that the link between oil and economic activity is not entirely linear and that there is strong evidence of asymmetric relationships between the two variables [Mork (1989), Hamilton (2003), Zhang (2008) and Lardic and Mignon (2006, 2008)]. Therefore, one possible explanation for our findings is that the traditional cointegration tests are too restrictive and cannot reproduce such asymmetric long-term relationships. In the rest of the paper, we test for asymmetric cointegration between oil prices and stock markets in Europe.

6 For comparison purposes, we reported in appendix B (Table B-1) the results of the basic cointegration tests: LStock $_{t}=\beta_{0}+\beta_{1} L O i l_{t}+\varepsilon_{t}$. 


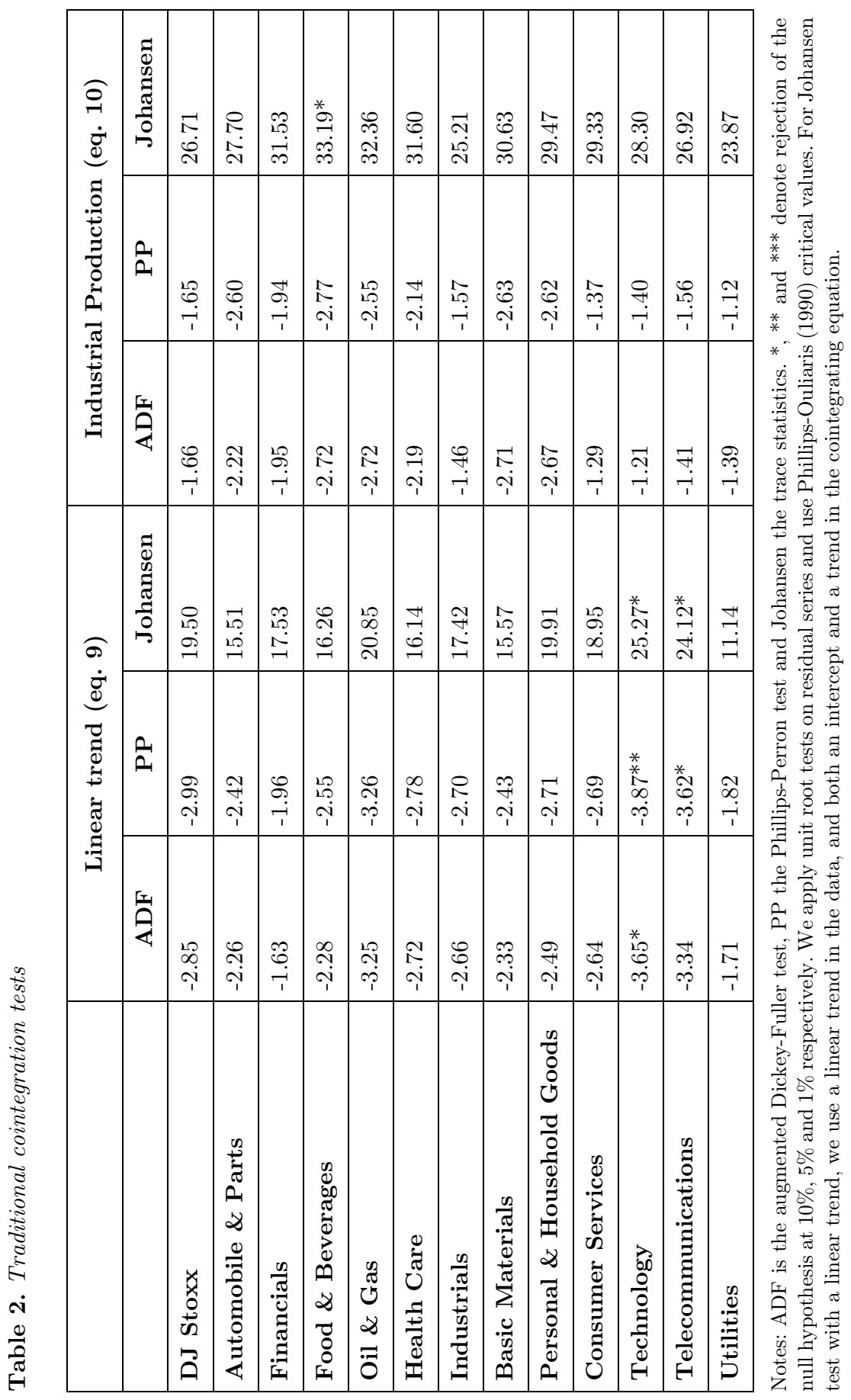




\subsection{Asymmetric cointegration tests}

In this step of our empirical investigation, we look at whether the decomposition of a time series into its positive or negative partial sum alters the conclusions of the traditional cointegration test. In other words, are there asymmetric cointegrating relationships between oil prices and European stock market indices?

As shown by Schorderet (2004), standard unit root and cointegration tests can be applied to check for asymmetric cointegration. We must then estimate the equations with a linear trend (equations (5) and (6)) and with industrial production (equations (7) and (8)) by OLS and test for the presence of unit root in the residual sequences $\xi_{1 t}$ and $\xi_{2 t} \cdot{ }^{7}$

As before, we follow the same methodology and apply the ADF, PP and Johansen tests. The results of cointegration tests are shown in Table 3 for equation (5) and (7) and in Table 4 for equations (6) and (8).

Consider first tests on $\xi_{1 t}$. In most cases, our findings show that there is no long-term relationship between stock prices and oil price decreases. The only exception is for Basic Materials stocks when we consider the equation including European industrial production. In Appendix B, we report the results based on equation (3). For all sectors, only the Johansen tests find cointegration. However, these results should be taken with a grain of salt, since this equation is misperceived and the Johansen tests applied to residuals of equation (3) have always concluded in cointegration at the $1 \%$ significance level.

Next, turn to tests on $\xi_{2 t}$. Strong evidence of asymmetric cointegration is found for the aggregate DJ Stoxx index as well as for most sector indices. Thus, our findings show the existence of significant long-term links between most sector stock prices and oil price increases. Moreover, the conclusion in favour of the existence of long-term relationships between stock price and oil price increases is stronger for sectors, such us Oil \& Gas and Automobile $\&$ Parts, highly dependent on oil.

Together, our findings suggest that the reaction of stock markets in Europe to oil prices depends on the sector and on the sign of the oil price changes. In particular, we show that the responses of sector stock prices to oil price increases are considerably larger than those to oil price decreases. Though an increase in oil prices seems generally to significantly affect the economy, the significance and direction of its effects on stock market prices may vary for other reasons. Indeed, the impact of oil price changes on an industry depends on whether oil is an input or an output for the industry, on the competition

7 For comparative purposes, we have also reported the results of Schorderet's methodology in Appendix B. More precisely, we have estimated equations (3) and (4) and used Phillips-Ouliaris (1990) to test for asymmetric cointegrating relationships. 


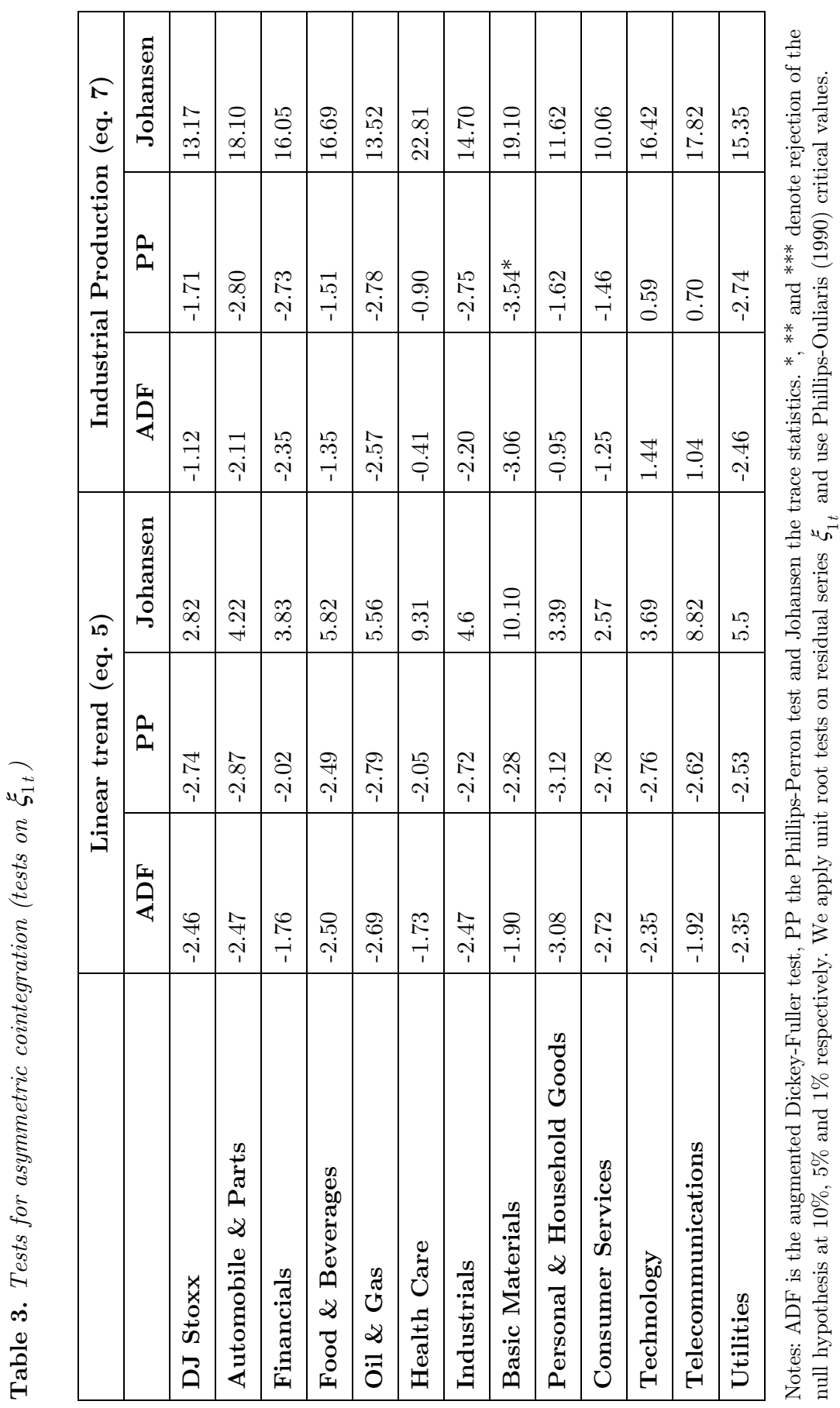




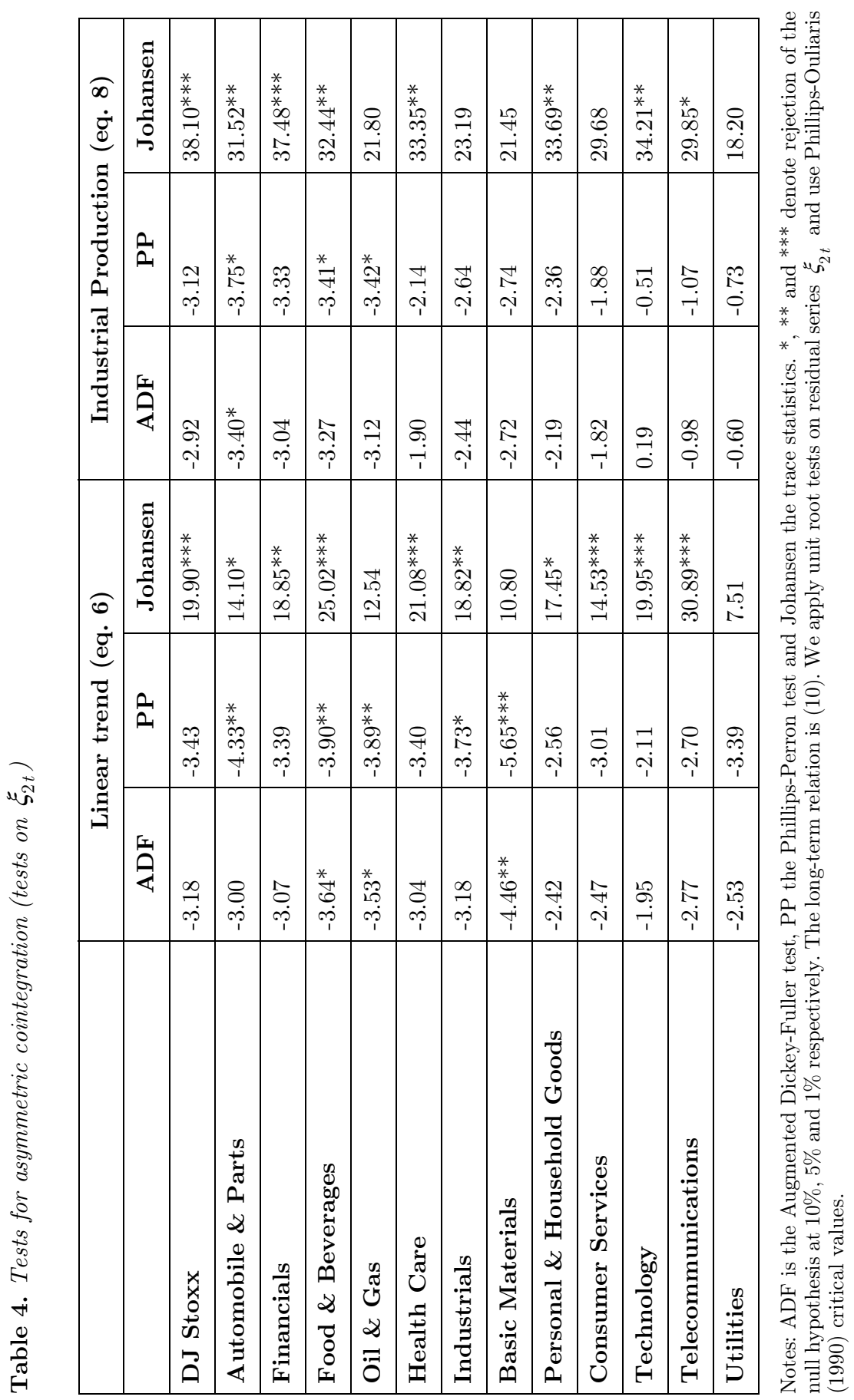


and concentration in the industry, and on the capacity of the industry to pass on increases in the price of oil to its consumers and thus to optimize its profitability, and finally on the effectiveness with which it uses futures contacts and other hedging techniques. In addition, related oil products are also linked to oil prices and have a direct impact on other industries such as Food $\mathscr{E} B e v$ erages, and Industrials. Finally, oil price changes also have indirect effects on some industries. For instance, oil price increases influence the financial sector through their effects on monetary policy, interest rates, employment and consumer confidence. As we discussed in section 2, these effects may be asymmetric, an asymmetry that is consistent with our findings.

As expected, there is evidence of asymmetric cointegration for several sectors in Europe. Thus, there are asymmetric long-term relationships between oil prices and several European sector indices, especially when oil prices increase. In what follows, we examine these long-term relationships.

\subsection{Long-term relationships}

Finally, we estimate the long-term asymmetric relationships between sector stock prices and oil price increases (equations (6) and (8)). Only the results for the indices for which cointegration was obtained are relevant. ${ }^{8}$ In Table 5 , the results are summarized for the specification with linear trend (equation (6)) and industrial production (equation (8)). As noted by Schorderet (2004), the significance levels of the coefficients are computed based on corrected standard errors (as a result of the presence of serial correlation in the residuals). We then follow West's (1988) methodology to obtain consistent estimates of the standard deviations.

As expected, the linear time trend coefficient, as well as the industrial production coefficient, is, in most cases, significant at the $1 \%$ level. Furthermore, in all cases these two coefficients have the same sign. More interestingly, the coefficients $\beta_{1}^{+}$are positive in most cases, suggesting that there are positive long-term relationships between sector stock prices and oil price increases. Therefore, our finding can be considered as evidence for the reverse causality put forward recently by Barsky and Killian (2004) and Killian $(2008,2009)$ : an increase in stock prices, reflecting a growth in general economic activity, would be associated with an increase in the oil price because of growing demand and investors and consumers confidence. However, the sensitivity of stock prices to oil price increases varies considerably from one sector to another.

8 When the cointegration hypothesis is rejected, the estimation of the long-term relationships is spurious. It is in particular the case of estimations, not reported here, of the long-term relationships between stock prices and oil price decreases (equations (5) and (7)). 


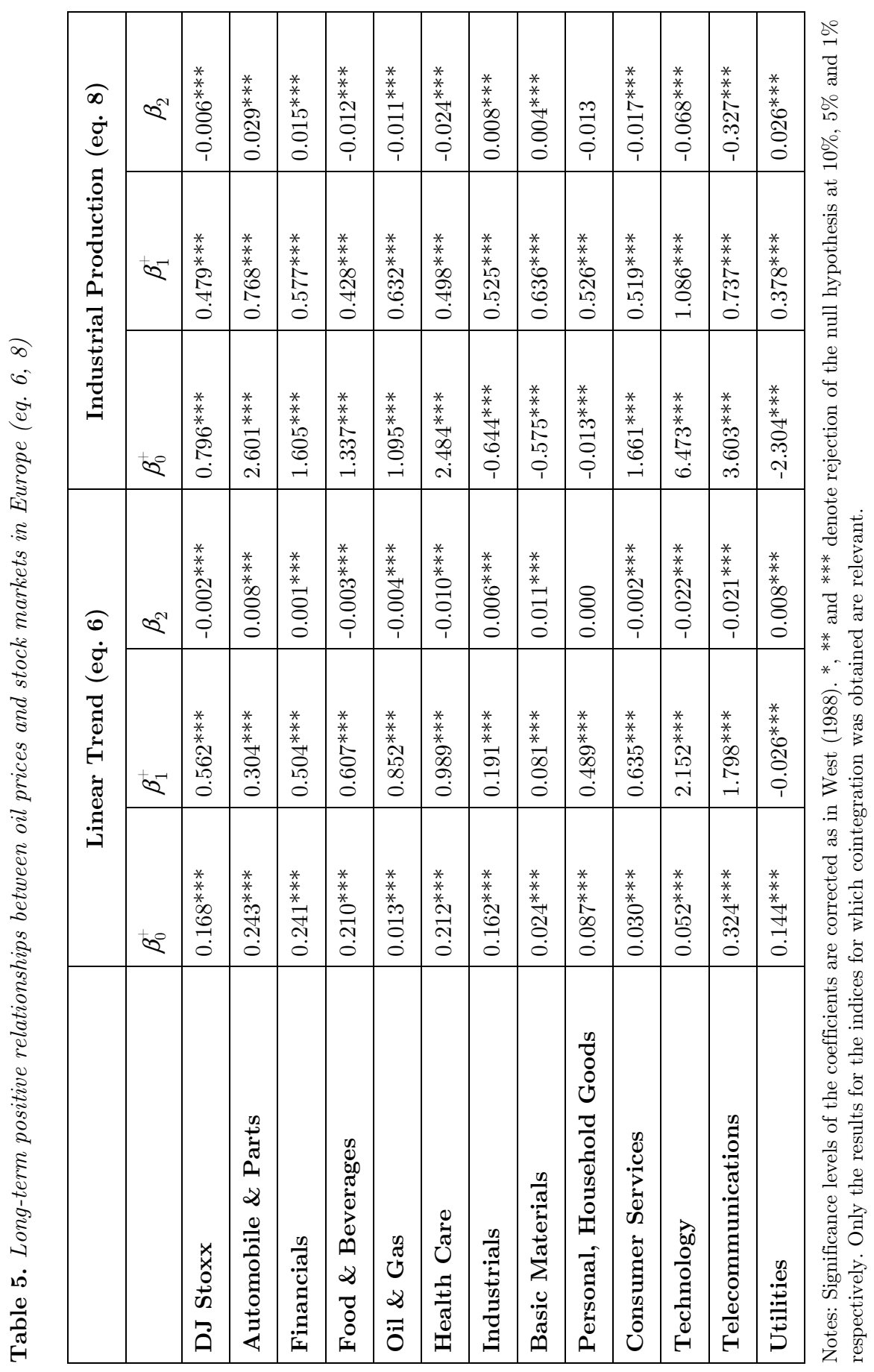


To sum up, as we discussed in Section 2, we expect that not all industries are equally dependent on oil and that oil price increases and decreases should affect stock prices differently. Our empirical results confirm the asymmetric responses of several European sector stock prices to oil price changes. More precisely, our findings suggest the existence of a double asymmetry in the oil-stock price relationships: the responses of stock prices to oil price changes depend both on the sector and on the sign of oil price changes. Indeed, we empirically show that oil price increases have a strong direct impact on the stocks of oil-intensive industries such as Automobile $\&$ Parts and Oil \& Gas as well as an indirect impact on the stocks of some non-oil-intensive industries such as Financials and Technology, mainly through the association during the last years between oil price increases and higher expected economic growth and demand for most products. Thus, our findings are consistent with those of previous works on the asymmetric responses of economic growth to oil price changes and suggest that transmission channels from oil price to the financial variables partly reflect transmission channels from oil prices to the real economy [Mork (1989), Davis and Haltiwanger (2001), Lee and Ni (2002), Lardic and Mignon (2006, 2008) and Cologni and Manera (2009)].

\section{$5 \quad$ Conclusion and policy implications}

In this article, we examine the long-term relationships between oil prices and stock markets. In contrast to previous empirical investigations, which have focused mostly on the aggregate index of the individual markets (national and/or regional indices) rather than on the individual sectors and used classic cointegration tests, we test for linear and asymmetric long-term links on both aggregate and sector levels. Our results show that the response of stock prices differ greatly from one sector of activity to another and that oil prices affect stock prices in an asymmetric fashion: rises in the price of oil have greater effects on stock prices than do falls in the price of oil. Overall, our findings can be interpreted as evidence for the reverse causality between stock markets and oil price increases: in the last years increases in oil prices were associated with higher expected economic growth and higher demand and investor and consumer confidence [Barsky and Killian (2004), and Killian (2008, 2009)].

The responses of stock prices to oil price increases are highly significant for oil-intensive industries such Automobile $\&$ Parts and Oil \& Gas. More interestingly, our results suggest that the stock prices of industries such as Financials and Technology, which are not directly affected by oil prices, are also sensitive to oil price increases. This finding suggests that the responses of stock prices to increases in the price of oil depend not only on the possible increases in marginal costs of production (cost-side effects) but also on the possible association between increasing oil prices and higher economic 
growth, consumer confidence and demand for most products (demand-side effects).

Our findings should be of interest to researchers, regulators, and market participants. First, our results could be used by traders to hedge against oil price changes or to build profitable speculation strategies. Second, the fact that sectors in Europe have different sensitivities to oil price changes means great risk diversification possibilities across industries in Europe. Therefore, selecting portfolios across sectors rather than within sectors would be more efficient. Finally, investors and portfolio managers should rebalance their portfolio compositions on the basis of the expected sign of oil price variations (increase or decrease of oil prices), and our findings suggest that benefits of diversification can be achieved across sectors in all cases of oil price changes.

The findings of the study offer several avenues for future research. First, evidence from international equity markets and other regions should be produced to examine the robustness of the findings. Second, the methodology we applied in this article could be used to examine the effects of changes in the prices of other energy products, such as natural gas. Finally, further research could investigate the short- and long-term linear and nonlinear causality between oil prices and stock markets in Europe and other regions.

\section{References}

Apergis N. and Miller S. M. (2009), "Do structural Oil-Market Shocks affect Stock Prices?" Energy Economics, 31, pp. 569-75.

Balaz, P., Londarev, A., (2006), "Oil and its Position in the Process of Globalization of the World Economy". Politická Ekonomie, 54 (4), pp. 508-528.

Barsky, R. and L. Killian (2004), "Oil and the macroeconomy since the 1970s", Journal of Economic Perspectives, 18(4), pp. 115-134.

Basher, S. A. and P. Sadorsky (2006) "Oil Price Risk and Emerging Stock Markets", Global Finance Journal, 17, pp. 224-251.

Boyer M.M. and Filion D. (2007), "Common and Fundamental Factors in Stock Returns of Canadian oil and Gas Companies", Energy Economics, 29(3), pp. 428-53.

Choi, I. and Saikkonen P. (2004), "Testing linearity in cointegrating smooth transition regressions", Econometrics Journal 7, pp. 341-346.

Ciner, C. (2001). "Energy Shocks and Financial Markets: Nonlinear Linkages." Studies in Non-Linear Dynamics and Econometrics, 5, pp. 203-12.

Cologni, A. and M. Manera (2008). "Oil prices, inflation and interest rates in a structural cointegrated VAR model for the G-7 countries." Energy Economics, 30, pp. 856-88. 
Cologni, A. and M. Manera (2009). "The Asymmetric Effects of Oil Shocks on Output Growth: A Markov-Switching Analysis for the G-7 Countries," Economic Modelling, 26, pp. 1-29.

Cunado, J., Perez de Garcia, F., 2005. "Oil prices, economic activity and inflation: evidence for some Asian countries." The Quarterly Review of Economics and Finance 45 (1), pp. 65-83.

Davis, SJ, and Haltiwanger J. (2001). "Sectoral Job Creation and Destruction Responses to Oil Price Changes," Journal of Monetary Economics, 48, pp. 465-512.

Dickey, D.A., and W.A. Fuller (1981), "Likelihood Ratio Statistics for Autoregressive Time Series with a Unit Root", Econometrica, 49(4), pp. 1057-72.

El-Sharif I, Brown D., Burton B., Nixon B., Russel A. (2005), "Evidence on the Nature and Extent of the Relationship between Oil and Equity Value in UK", Energy Economics, 27(6), pp. 819-830.

Engle, R.F., and C.W.J. Granger (1987), "Co-integration and Error Correction: Representation, Estimation, and Testing “, Econometrica, 55(2), pp. 251-76.

Ferderer, J. P. (1996), "Oil Price Volatility and the Macroeconomy", Journal of Macroeconomics 18 1, pp. 1-26

Gronwald, M. (2008). "Large oil shocks and the US economy: Infrequent incidents with large effects," Energy Journal, 29, pp. 151-71.

Hamilton, J. D. (1988), "A Neoclassical Model of Unemployment and the Business Cycle", Journal of Political Economy, 96, pp. 593-617.

Hamilton, J. D. (2003). "What is an Oil Shock?" Journal of Econometrics, 113, pp. 363-98.

Hamilton, J.D. (1983), "Oil and the Macroeconomy since World War II", Journal of Political Economy 91, pp. 228-248.

Hammoudeh, S. and K. Choi. (2006) 'Behavior of GCC Stock Markets and Impacts of US Oil and Financial Markets', Research in International Business and Finance, Vol. 20 no. 1, pp. 22-44.

Huang, R. D., Masulis, R. W., and H. R. Stoll (1996). "Energy shocks and financial markets", Journal of Futures Markets, 16, pp. 1-27.

Johansen S. (1991), "Estimation and Hypothesis Testing of Cointegration Vectors in Gaussian Vector Autoregressive Models", Econometrica, 59, pp. 1551-1580.

Jones, C.M., Kaul, G. (1996), "Oil and the Stock Markets", Journal of Finance, vol. 51, n 2, pp. 463-491.

Jones, D. W., Lelby, P. N. and Paik, I. K. (2004), "Oil Prices Shocks and the Macroeconomy: What Has Been Learned Since", The Energy Journal, 25, pp. 1-32.

Kilian, L., (2008). "Exogenous Oil Supply Shocks: How Big Are They and How Much Do They Matter for the US Economy?" Review of Economics and Statistics, 90, pp. 216-40.

Killian, L. (2009), "Not all oil price shocks are alike: Disentangling demand and supply shocks in the crude oil market", American Economic Review, 99(3), 1053-69.

Kwiatkowski, D., Phillips, P. and Y. Shin, (1992), "Testing for the Null Hypothesis of Stationarity against the Alternative of a Unit Root", Journal of Econometrics 54, pp. 159-178. 
Lardic S. and Mignon V. (2006), "The impact of oil prices on GDP in European countries: An empirical investigation based on asymmetric cointegration", Energy Policy, vol. 34(18), pp. 3910-3915.

Lardic S. and Mignon V. (2008), "Oil prices and economic activity: An asymmetric cointegration approach", Energy Economics, vol. 30(3), pp. 847-855.

Lee, K., and S. Ni. (2002) "On the Dynamic Effects of Oil Price Shocks: A Study Using Industry Level Data," Journal of Monetary Economics 49, pp. 823-852.

Maghyereh, A. (2004), "Oil price shocks and emerging stock markets: a generalised VAR approach", International Journal of Applied Econometrics and Quantitative Studies 1, pp. 27-40.

Mork K. (1989), "Oil and the Macroeconomy when prices Go Up and Down: an Extension of Hamilton's Results", Journal of Political Economy, 91, pp. 740-744.

Mork, K.A., Olsen, O. and Mysen, H.T. (1994), "Macroeconomic responses to oil price increases and decreases in seven OECD countries", Energy Journal 15 , pp. 19-35.

Nandha M. and Faff R. (2008), "Does Oil Move Equity Prices? A Global View", Energy Economics, 30, pp. 986-97.

Nandha, M. and Brooks, R. (2009), 'Oil prices and transport sector returns: an international analysis', Review of Quantitative Finance and Accounting, 33(4).

Nandha, M., and Hammoudeh, S. (2007), "Systematic Risk, and Oil Price and Exchange Rate Sensitivities in Asia-Pacific Stock Markets", Research in International Business and Finance 21, pp.326-41.

Newey, W. K., and K. D. West (1994). "Automatic Lag Selection in Covariance Matrix Estimation", Review of Economic Studies, 61(4), pp. 631-653.

Papapetrou, E. (2001). "Oil Price Shocks, Stock Market, Economic Activity and Employment in Greece," Energy Economics, 23, pp. 511-32.

Park, J. and Ratti R.A. (2008),"Oil Price Shocks and Stock Markets in the US and 13 European Countries", Energy Economics, 30, pp. 2587-2608.

Sadorsky P. (2001), "Risk Factors in Stock Returns of Canadian Oil and Gas Companies", Energy Economics, 23, pp. 17-28.

Sadorsky, P. (1999), Oil Price Shocks and Stock Market Activity, Energy Economics, vol. 2, pp. 449-469.

Schorderet, Y. (2004), "Asymmetric Cointegration", Working Paper, Department of Econometrics, University of Geneva.

Shen, C.H., Chen C.F. and Chen, L.H. (2007), "An empirical study of the asymmetric cointegration relationships among the Chinese stock markets", Applied Economics, vol. 39, $\mathrm{n}^{\circ} 11$, pp. 1433-1445(13);

West K.D. (1988), "Asymptotic normality when regressors have a unit root", Econometrica, 56, pp. 1397-1417.

Zhang D. (2008),"Oil shock and economic growth in Japan: A nonlinear approach", Energy Economics, vol. 30, issue 5, pp. 2374-2390. 


\section{Appendix A on Schorderet (2004) asymmetric cointegration approach}

By distinguishing its positive and negative increments, any time series $\left\{y_{t}\right\}_{t=0}^{T}$ can be broken down into its initial value and its negative and positive cumulative sums:

$$
y_{t}=y_{0}+y_{t}^{+}+y_{t}^{-}
$$

where $y_{0}$ is the initial value and:

$$
y_{t}^{+}=\sum_{i=0}^{t-1} 1\left\{\Delta y_{t-i} \geq 0\right\} \Delta y_{t-i}
$$

and

$$
y_{t}^{-}=\sum_{i=0}^{t-1} 1\left\{\Delta y_{t-i}<0\right\} \Delta y_{t-i}(\mathrm{~A}-3)
$$

$1\{$.$\} is the indicator function taking 1$ if the event in brackets occurs and zero otherwise.

Next, consider two non-stationary time series $y_{1 t}$ and $y_{2 t}$. Suppose that there is a linear combination $z_{t}$ of their components such that:

$$
z_{t}=\beta_{1} y_{1 t}^{+}+\beta_{2} y_{1 t}^{-}+\beta_{3} y_{2 t}^{+}+\beta_{4} y_{2 t}^{-}
$$

If there is a vector $\beta^{\prime}=\left(\beta_{1}, \beta_{2}, \beta_{3}, \beta_{4}\right)$ with $\beta \neq 0, \beta_{1} \neq \beta_{2}$ and $\beta_{3} \neq \beta_{4}$ such as $z_{t}$ is a stationary process, the time series $y_{1 t}$ and $y_{2 t}$ are said to be asymmetrically co-integrated.

Now, suppose that only one component of each series appears in the cointegrating relationship (A-4). This may be seen as a co-integration relation that "operates" in only one direction:

$$
y_{1 t}^{+}=\beta^{+} y_{2 t}^{+}+z_{1 t} \quad t=1, \ldots, T
$$

or

$$
y_{1 t}^{\bar{t}}=\beta^{-} y_{2 t}^{-}+z_{2 t} \quad t=1, \ldots, T
$$

Because of the non-linear characteristics of $z_{t}$, OLS estimate of (A-5) and (v6) is likely to be biased in a finite sample and the usual techniques of statistical inference are misspecified. Schorderet (2004) suggests using OLS to estimate the auxiliary models (A-7) and (A-8). As proven by West (1988), under fairly general conditions the OLS estimate of (A-7) and (A-8) is asymptotically normal and statistical inference can then proceed in the usual way:

$$
y_{1 t}^{-}+\Delta y_{1 t}^{+}=\beta^{-} y_{2 t}^{-}+\xi_{1 t}
$$


or

$$
y_{1 t}^{+}+\Delta y_{1 t}^{-}=\beta^{+} y_{2 t}^{+}+\xi_{2 t}
$$

To test for no co-integration against asymmetric co-integration, the traditional Engle and Granger procedure can be applied to (A-7) and (A-8) instead of (A-5) and (A-6).

\section{Appendix B on Schorderet (2004) original specifications (equations (3) and (4))}

Table B-1. Traditional cointegration tests

\begin{tabular}{|l|l|l|l|}
\hline & \multicolumn{1}{|c|}{ ADF } & \multicolumn{1}{c|}{ PP } & Johansen \\
\hline DJ Stoxx & -1.32 & -1.25 & 7.09 \\
\hline Automobile \& Parts & -2.08 & 2.22 & 8.14 \\
\hline Financials & -0.65 & -1.25 & 6.62 \\
\hline Food \& Beverages & $-2.69^{*}$ & $-2.76^{* *}$ & 12.26 \\
\hline Oil \& Gas & -2.31 & -2.24 & 9.5 \\
\hline Health Care & -2.00 & -2.05 & 6.06 \\
\hline Industrials & -1.44 & -1.26 & 6.62 \\
\hline Basic Materials & -2.39 & -2.35 & 9.53 \\
\hline Personal \& Household Goods & -2.37 & -2.34 & 12.4 \\
\hline Consumer Services & -1.23 & -0.91 & 7.55 \\
\hline Technology & -1.68 & -1.39 & 6.52 \\
\hline Telecommunications & -1.61 & -1.58 & 7.03 \\
\hline Utilities & -1.59 & -1.57 & 5.37 \\
\hline
\end{tabular}

Notes: ADF is the augmented Dickey-Fuller test, PP the Phillips-Perron test and Johansen the trace statistics. $*, * *$ and $* * *$ denote rejection of the null hypothesis at $10 \%, 5 \%$ and $1 \%$ respectively. The long-term relation is $L S t o c k_{t}=\beta_{0}+\beta_{1} L O i l_{t}+\varepsilon_{t}$. We apply unit root tests on residual series $\varepsilon_{t}$. 
Table B-2. Tests for asymmetric cointegration in equation 3 (tests on $\xi_{1 t}$ )

\begin{tabular}{|l|l|l|l|}
\hline & \multicolumn{1}{|c|}{ ADF } & \multicolumn{1}{c|}{ PP } & Johansen \\
\hline DJ Stoxx & -1.61 & -1.81 & $60.2^{* * *}$ \\
\hline Automobile \& Parts & -2.09 & -2.42 & $54.7^{* * *}$ \\
\hline Financials & -1.5 & -1.75 & $53.59^{* * *}$ \\
\hline Food \& Beverages & -1.76 & -2.07 & $66.54^{* * *}$ \\
\hline Oil \& Gas & -2.3 & -2.50 & $74.4^{* * *}$ \\
\hline Health Care & -1.24 & -1.37 & $74.4^{* * *}$ \\
\hline Industrials & -1.92 & -2.17 & $50.71^{* * *}$ \\
\hline Basic Materials & 1.85 & -2.24 & $59.84^{* * *}$ \\
\hline Personal \& Household Goods & -1.69 & -1.94 & $65.6^{* * *}$ \\
\hline Consumer Services & -1.66 & -1.75 & $69.24^{* * *}$ \\
\hline Technology & -0.64 & -0.84 & $71.4^{* * *}$ \\
\hline Telecommunications & -0.17 & -0.37 & $85.9^{* * *}$ \\
\hline Utilities & -2.05 & -2.28 & $63.16^{* * *}$ \\
\hline
\end{tabular}

Notes: ADF is the Augmented Dickey-Fuller test, PP the Phillips-Perron test and Johansen the trace statistics. ${ }^{*},{ }^{* *}$ and ${ }^{* * *}$ denote rejection of the null hypothesis at $10 \%, 5 \%$ and $1 \%$. The long-term relation is (3). We apply unit root tests on residual series $\xi_{1 t}$.

Table B-3. Tests for asymmetric cointegration in equation 4 (tests on $\xi_{2 t}$ )

\begin{tabular}{|l|l|l|l|}
\hline & ADF & PP & Johansen \\
\hline DJ Stoxx & $-3.02^{*}$ & $-3.24^{*}$ & $60.2^{* * *}$ \\
\hline Automobile \& Parts & -2.63 & $-3.05^{*}$ & $135.4^{* * *}$ \\
\hline Financials & $-3.11^{*}$ & $-3.43^{* *}$ & $131.7^{* * *}$ \\
\hline Food \& Beverages & $-3.36^{* *}$ & $-3.44^{* *}$ & $139.9^{* * *}$ \\
\hline Oil \& Gas & -2.52 & $-3.10^{*}$ & $120.0^{* * *}$ \\
\hline Health Care & -2.2 & -2.51 & $144.3^{* * *}$ \\
\hline Industrials & -2.96 & -2.81 & $152.5^{* * *}$ \\
\hline Basic Materials & -2.37 & -2.87 & $133.4^{* * *}$ \\
\hline Personal \& Household Goods & -1.84 & -2.60 & $185.1^{* * *}$ \\
\hline Consumer Services & -2.13 & -2.22 & $119.4^{* * *}$ \\
\hline Technology & -0.85 & -0.94 & $122.8^{* * *}$ \\
\hline Telecommunications & -1.48 & -1.64 & $138.8^{* * *}$ \\
\hline Utilities & -1.59 & -2.01 & $142.3^{* * *}$ \\
\hline
\end{tabular}

Notes: ADF is the augmented Dickey-Fuller test, PP the Phillips-Perron test and Johansen the trace statistics. $*, * *$ and $* * *$ denote rejection of the null hypothesis at $10 \%, 5 \%$ and $1 \%$ respectively. The long-term relation is (4). We apply unit root tests on residual series $\xi_{2 t}$. 
Table B-4. Long-term relationships between oil prices and stock markets in Europe (equations 3 and 4)

\begin{tabular}{|l|c|l|l|l|}
\hline & \multicolumn{2}{|c|}{ Equation 3 } & \multicolumn{2}{c|}{ Equation 4} \\
\hline & $\beta_{0}$ & $\beta_{1}$ & $\beta_{0}$ & $\beta_{1}^{+}$ \\
\hline DJ Stoxx & $0.178^{* * *}$ & $0.575^{* * *}$ & $0.199^{* * *}$ & $0.468^{* * *}$ \\
\hline Automobile \& Parts & $0.206^{* * *}$ & $0.874^{* * *}$ & $0.104^{* * *}$ & $0.720^{* * *}$ \\
\hline Financials & $0.167^{* * *}$ & $0.678^{* * *}$ & $0.225^{* * *}$ & $0.550^{* * *}$ \\
\hline Food \& Beverages & $-0.065^{* * *}$ & $0.4637^{* * *}$ & $0.277^{* * *}$ & $0.408^{* * *}$ \\
\hline Oil \& Gas & $0.1645^{* * *}$ & $0.714^{* * *}$ & $0.105^{* * *}$ & $0.6135^{* * *}$ \\
\hline Health Care & $-0.038^{* * *}$ & $0.567^{* * *}$ & $0.388^{* * *}$ & $0.458^{* * *}$ \\
\hline Industrials & $0.298^{* * *}$ & $0.652^{* * *}$ & $0.046^{* * *}$ & $0.538^{* * *}$ \\
\hline Basic Materials & $0.272^{* * *}$ & $0.687^{* * *}$ & $-0.164^{* * *}$ & $0.644^{* * *}$ \\
\hline Personal, Household Goods & $0.180^{* * *}$ & $0.571^{* * *}$ & $0.082^{* * *}$ & $0.504^{* * *}$ \\
\hline Consumer Services & $0.310^{* * *}$ & $0.652^{* * *}$ & $0.08^{* * *}$ & $0.489^{* * *}$ \\
\hline Technology & $0.617^{* * *}$ & $1.306^{* * *}$ & $0.447^{* * *}$ & $0.971^{* * *}$ \\
\hline Telecommunications & $0.197^{* * *}$ & $0.916^{* * *}$ & $0.698^{* * *}$ & $0.681^{* * *}$ \\
\hline Utilities & $0.150^{* *}$ & $0.458^{* * *}$ & $-0.005^{* * *}$ & $0.421^{* * *}$ \\
\hline
\end{tabular}

Notes: Significance levels of the coefficients are corrected as in West (1988). *, ** and *** denote rejection of the null hypothesis at $10 \%, 5 \%$ and $1 \%$ respectively. Only the results for the indices for which cointegration was obtained are relevant. 